\title{
Morphological, pathogenic and genetic diversity of Botrytis cinerea Pers. in blackberry cultivations in Colombia
}

\author{
Liliana Isaza $^{1}$, Yenni Paola Zuluaga ${ }^{2}$ y Marta Leonor Marulanda ${ }^{3}$

\begin{abstract}
The Andean blackberry (Rubus glaucus Benth) is one of the most important fruits with the greatest commercial projection in Colombia. The factors that most affect its production are the attack of diseases and the scarce information about its control. One of the most limiting diseases of the crop is the gray mold, produced by the fungus Botrytis cinerea. This research presents the diversity of $B$. cinerea isolates from fields of andean blackberry in Colombia, based on the morphological, pathogenic and genetic characteristics allowing broadening the knowledge of the phytopathogen for subsequent management measures. Andean blackberry fruits were collected with characteristic symptoms of gray mold in farms located in eight producing areas of Colombian Andean region. A total of 50 samples were analyzed finding two types of growth, miceliar and sclerocial, differences in the layout and size of the sclerotia, as well as differences in the daily growth of the mycelium. Regarding genetic characterization with microsatellite markers, it was shown that genetic diversity is concentrated within populations and that there is a tendency to group by geographical origin. With the pathogenicity tests, the two most pathogenic isolates were selected and it was found that, although the four possible genotypes were found with the transposable elements (Vacuma, Transposa, Boty, Flipper), none of them presented high resistance to the fungicide fenhexamide.
\end{abstract}

Index terms: Gray mold, Boty, Flipper, fungal resistance.

\section{Diversidade morfológica, patogênica e genética de Botrytis cinerea Pers. em lavouras de amora-preta var. Castilla na Colômbia}

Corresponding author: lilisaza@utp.edu.co

Received: April 25, 2019 Accepted: October 07, 2019

Copyright: All the contents of this journal, except where otherwise noted, is licensed under a Creative Commons Attribution License.

\section{$($ (cc) $\mathbf{E Y}$}

Resumo-A amora-preta (Rubus glaucus Benth) é uma das frutas mais importantes e com a maior projeção comercial da Colômbia. Os fatores que mais afetam sua produção são o ataque de doenças e a pouca informação sobre o seu controle. Uma das doenças mais limitantes no cultivo é o mofo cinzento, produzido pelo fungo Botrytis cinerea. Esta pesquisa apresenta a diversidade de isolados de $B$. cinerea presentes nas culturas de amora-preta na Colômbia, com base em características morfológicas, patogênicas e genéticas, permitindo ampliar o conhecimento do fitopatógeno para adotar medidas de manejo subsequentes. Frutos de amora-preta com sintomas característicos de mofo-cinza foram coletados em fazendas localizadas em oito departamentos produtores de amorapreta da região andina colombiana. Um total de 50 amostras foram analisadas, encontrando-se dois tipos de crescimento, micelial e esclerodial, diferenças na disposição e no tamanho dos escleródios, bem como diferenças no crescimento diário do micélio. Com relação à caracterização genética com marcadores microssatélites, demonstrou-se que a diversidade genética está concentrada no interior das populações e que há uma tendência de agrupar-se por origem geográfica. Com os testes de patogenicidade, os dois isolados mais patogênicos foram selecionados e ficou evidente que, embora os quatro genótipos possíveis tenham sido encontrados com os elementos transponíveis (Vacuma, Transposa, Boty, Flipper), nenhum deles apresentou alta resistência ao fungicida fenhexamida. Termos para indexação: Mofo cinzento, Boty, Flipper, resistência a fungos.

${ }^{1} \mathrm{PhD}$. Universidad Tecnológica de Pereira. Plant Biotechnology Laboratory. Pereira-Risaralda, Colombia. Email: lilisaza@utp.edu.co(Orcid 0000-0002-6055-6575)

${ }^{2}$ Biologist. Universidad Tecnológica de Pereira. Plant Biotechnology Laboratory. Pereira-Risaralda, Colombia.Email: ypzp429@gmail.com ${ }^{\text {(ORcID }}$ 0000-0002- 5497-6012)

${ }^{3} \mathrm{PhD}$. Universidad Tecnológica de Pereira. Office of the Vice-Rectory for Research, Innovation and Extension. Pereira-Risaralda, Colombia. Email: mlmarulanda@utp.edu.co (ORCID 0000-0002-0748-7582) 


\section{Introduction}

The Andean blackberry (Rubus glaucus, Benth) is one of the most prominent fruits with the eminent commercial production in Colombia. It is cultivated by small and medium farmers, and is one of the primary sources of income, rural employment, and agro-industrial alternatives (BOTERO and FRANCO, 2007). The cultivation of the Andean blackberry (also known as the Mora de Castilla) has increased considerably in recent years with the increase in the national demand for the fruit for both fresh and agribusiness consumption, as well as for export. It is rapidly growing into a productive alternative, which is generating income for the producers (LA-ROTTA, 2001). Despite its recognized importance in generating income, this crop has seen little technological development. Its quality and productivity are highly variable, mainly due to the lack of recognized varieties and planting materials with genetic and phytosanitary qualities.

The attacks of diseases with scarce information about their control serve as the main factor that affects the production of this crop. One of the most limiting diseases of the crop is gray mold, which is caused by the fungus, Botrytis cinerea (DASHWOOD AND FOX, 1998; MOLINA et al. 2004). This disease is considered to be one of the most common and serious diseases caused by the genus Rubus. It affects another 200 crops of agricultural importance (MOLINA et al. 2004; ZHOU et al. 2014).

Tamayo and Peláez (2000) have reported production losses between $50 \%$ and $76 \%$ in blackberry fruit in Colombia due to this etiological agent. Recent studies have identified the existence of multiple cryptic species that are identified by a single species name (FEKETE et al. 2012). Thus, Botrytis cinerea is considered to be a complex system of species, instead of a single variable organism in which two sympatric groups have been identified by multiple gene genealogies (FOURNIER et al. 2005). These factors have created considerable genetic variation within the population, thereby affecting the phenotypic characteristics and reproduction modes and also causing an increase in the adaptability and structure of the populations (GIRAUD et al. 1997; PANDE et al. 2010). However, these groups exhibit marked differential characteristics that can be used as phenotypic markers. Recent studies have concluded that $B$. cinerea Group $\mathrm{I}$ is resistant to the fungicide Fenhexamid and has a characteristic volume of asexual spores (FEKETE et al. 2012), whereas $B$. cinerea Group II has reported sensitivity to Fenhexamid (ISENEGGER et al. 2008).

Additionally, the species that make up the complex $B$. cinerea system have revealed the presence of two transposons, Boty and Flipper, in their genomes. This, in turn, creates another mode of taxonomic grouping and increases the variability in species (PANDE et al. 2006), thereby making it possible to distinguish the groups, $B$. cinerea variety Transposa $(B c t)$, which has one or both of the two transposable elements, and the group, B. cinerea variety Vacuma $(B c v)$, which does not have either of the elements (ZHOU et al. 2014). As a result, these groups have displayed a remarkable geographical distribution pattern since the isolation of species associated with the Boty transposon has been reported mainly in Europe and Australia, whereas the isolation of species associated with the Flipper transposon has only been detected in South Eastern Europe (VERCESI et al. 2014). In addition, Beever and Weeds (2004) state that there are no species, which belong to Group I, that have been detected in Australia and Southern Asia; however, there are two cryptic species present in Europe and America. Therefore, a clear relationship is observed between Group I of $B$. cinerea and the content of transposable elements.

These factors create the need for studies whose aim is to measure and characterize the genetic diversity of local species of $B$. cinerea. In addition, this studies need to define the best management strategies for this phytopathogen (KUMARI et al. 2014). Although, it has been concluded that the application of fungicides does not induce transposon distribution patterns (VERCESI et al. 2014); however, the excessive application of these products mediates the occurrence of resistance phenomena and increased pathogenicity in fungi such as $B$. cinerea (ALVAREZ et al. 2017; GEEP et al. 2012).

Although there have been numerous studies of the morphological, pathogenic, and genetic diversities of Botrytis cinerea in different parts of the world (FEKETE et al. 2012; ZHOU et al. 2014; VERCESI et al. 2016), there are no reports that indicate the current status of this phytopathogen in Colombia associated with Andean blackberry crops. The purpose of this study is to show the diversity of $B$. cinerea isolates present in the Andean blackberry crops in Colombia on the basis of morphological, pathogenic, and genetic characteristics which allow for increased awareness of the phytopathogen. As a result, measures would be identified regarding its control.

\section{Materials and Methods}

\section{Plant material}

Andean blackberry fruit with the characteristic symptoms of gray mold (Figure 1) were collected from the farms located in eight blackberry-producing departments of the Colombian Andean region. In total, 50 samples were obtained and labeled according to their place of origin (Table 1). The farms visited were located at an altitude of 1,800-2,200 $\mathrm{m}$, with an average temperature of $16^{\circ} \mathrm{C}$ and annual rainfall exceeding $2,000 \mathrm{~mm}$. 

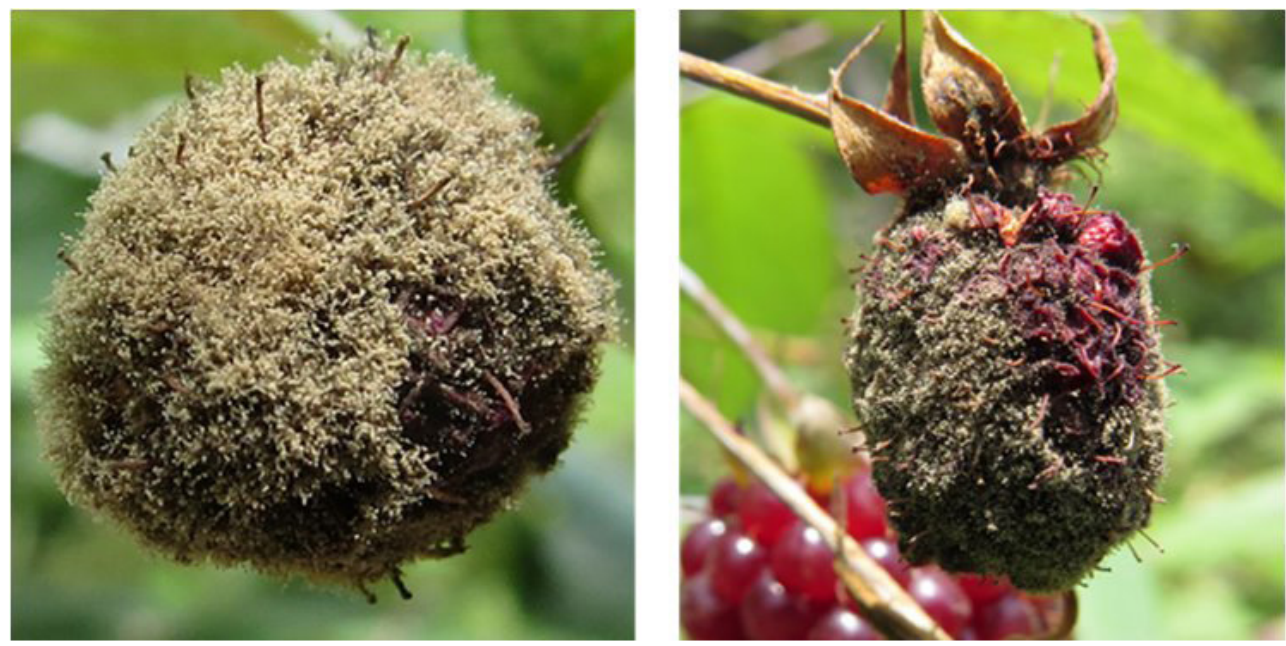

Figure 1. Gray mold produced by Botrytis cinerea in blackberries.

\section{Pathogen isolation}

The infected fruit was taken to the Plant Biotechnology Laboratory of the Universidad Tecnológica de Pereira. Small slices of the diseased tissue were acquired from the fruits that had the greatest sporulation, and four fragments of the tissue were placed in the petri dishes with potato dextrose agar (PDA) and incubated at $23^{\circ} \mathrm{C}$ in the dark. All samples were streak seeded until the sporulation of the fungus was achieved. Finally, the monosporic cultures of each of the isolates were carried out following the methodology proposed by CASTELLANOS et al. (2011) with slight modifications.

\section{Identification and morphological characterization}

The isolates were identified on the basis of their phenotypic characteristics, such as appearance and coloration of the mycelium along with the microscopic observations of conidiophores and conidia, which corresponded to the previously reported descriptions (CROUS et al. 2009; ELLIS, 1971) in the case of Botrytis cinerea. The isolates, previously visualized by optical microscopy, were observed by using a FEI brand scanning electron microscope of Quanta 250 model (Thermo Fisher Scientific).

The in vitro growth rate was determined by transferring a disc of fungal material with a defined diameter $(5 \mathrm{~mm})$. Thereafter, ten replications of each of the isolates were prepared in which daily mycelium growth (horizontal and vertical) was recorded. These measurements were carried out until the total surface of the petri dish $(92 \mathrm{~mm})$ was covered by the fungus. The average growth rates of each of the growths were determined for the purpose of statistical analyses.

To define the type of mycelium, three aspects were defined after 20 days of fungus growth: sparse mycelium (0), erumpent mycelium (1), and mycelium with mass growth (2) (MARTÍNEZ et al. 2003).
The distribution of the sclerotia of each of the isolates was observed on the 20th day after inoculation in a PDA medium. A total of ten petri dishes were selected for each isolation. These petri dishes were classified based on the types of distribution suggested by (TANOVIĆ et al. 2009), with some modifications: (E1) sclerotia only on the edge, (E2) sclerotia arranged radially, (E3) large and irregularly distributed sclerotia, (E4) numerous small and scattered sclerotia, and (E5) without sclerotia. In terms of size, for each isolation, five petri dishes were selected and ten sclerotia from each one were chosen at random. Each of them were measured, and the data were subsequently averaged for the respective statistical analyses.

On the 20th day after seeding, the mycelium colors of each of the isolates were evaluated. For this purpose, the RAL color chart (SANHUEZA, 2012) was employed as a reference, and a number was assigned to each isolate according to its color and intensity.

\section{Genetic characterization \\ DNA extraction}

The mycelium from each of the isolates was extracted after 20 days of growth in the PDA medium by using the commercial Plant DNeasy Mini Kit (QIAGEN) after following the manufacturer's instructions.

\section{Sample characterization with microsatellite (SSR) markers}

Genetic characterization with microsatellite molecular markers was performed via PCR amplification of DNA samples from each of the isolates. As previously reported by Fournier et al. (2002), nine microsatellites primers were used for this purpose.

The amplification reactions were prepared in a final volume of $12.5 \mu \mathrm{L}$ with $0.3 \mu \mathrm{M}$ of each of the primers, 15 $\mu \mathrm{M}$ of each dNTP, $1 \mathrm{X}$ of reaction buffer $(10 \mathrm{mM}$ of Tris $\mathrm{HCl}, 50 \mathrm{mM}$ of $\mathrm{KCl}$ ), $1 \mathrm{U}$ of Taq polymerase, and $2 \mathrm{mM}$ of $\mathrm{MgCl} 2$ and $10 \mathrm{ng} / \mu \mathrm{L}$ of DNA. A 32-cycle touchdown PCR program was performed with denaturation at $95^{\circ} \mathrm{C}$ 
for 60 seconds; pairing for $60 \mathrm{~s}$ with a decrease of $1^{\circ} \mathrm{C}$ in every two cycles from $64^{\circ} \mathrm{C}$ to $59^{\circ} \mathrm{C}, 10$ cycles at $58^{\circ} \mathrm{C}$, and 10 cycles at $57^{\circ} \mathrm{C}$; elongation at $72^{\circ} \mathrm{C}$ for 60 seconds; and a final extension at $72^{\circ} \mathrm{C}$ for $5 \mathrm{~min}$. The separation of the amplified products was carried out by electrophoresis in denaturing gels of $6 \%$ polyacrylamide. These amplified products were subsequently stained with silver nitrate following the protocol set out by Benbouza et al. (2006).

\section{Evaluation of the pathogenicity of $B$. cinerea} isolates

The pathogenicity test was performed by inoculating the healthy ripe Andean blackberries for the determination of the latency period and incubation of the fungus in each of the isolates. A concentration of $1.2 * 10^{6} \mathrm{ml}^{-1}$ conidia was used for these tests, and a suspension of fungus spores was prepared in sterile and distilled water. Healthy fruits were disinfected by using $70 \%$ alcohol for 2 minutes. Thereafter, the fruits were rinsed consecutively for three times with sterile and distilled water. The fruits were then submerged in $1 \%$ hypochlorite and again rinsed consecutively for three times with sterile and distilled water. As a control, some fruits were inoculated with sterile water. All fruits were punctured with a sterile needle and, then, sprinkled with the fungus suspension. The sprinkled fruits were kept in humid chambers at the room temperature, with observations taken every 24 hours. Subsequently, a rating was given to each fruit following a severity scale of 1-4, until the fruit was totally affected. The score of 1 was synonymous with a healthy fruit and 4 was synonymous to the fruit with the presence of mycelium greater than $75 \%$ of its area.

Each of the fungi belonging to each sampling area was inoculated. For each test, five repetitions were performed for each five fruits. Each of the fruits was subsequently evaluated with the aforementioned scale, and, finally, the two most pathogenic isolates were selected.

Determination of the presence/absence of Boty and Flipper transposons in $\boldsymbol{B}$. cinerea isolates

The presence of associated transposable elements (Boty and Flipper) was evaluated by using primers LTR98 (5' - AGCCTGTAGAATCACCAACG-3') and LTR728 (5-CGGTATTTCTGGTTGGCA-3) for Boty (FERRADA et al. 2016), and F300 (5'-GCACAAAACCTACAGAAGA-3') and F1550 (5-ATTCGTTTCTTGGACTGTA-3) for Flipper (MA AND MICHAILIDES, 2005). The reaction conditions consisted of a final volume of $12.5 \mu \mathrm{L}(0.4 \mu \mathrm{M}$ of each of the primers, $0.2 \mathrm{mM}$ of each dNTP, $1 \mathrm{X}$ of reaction buffer $(10 \mathrm{mM}$ of Tris $\mathrm{HCl}, 50 \mathrm{mM}$ of $\mathrm{KCl}), 1 \mathrm{U}$ of Taq polymerase, $2 \mathrm{mM} \mathrm{MgCl}$, and $10 \mathrm{ng} / \mu \mathrm{L}$ of DNA) and the touchdown temperature profile that is described above. The purified products were visualized on a $2 \%$ agarose gel.

\section{Determination of the susceptibility of $B$. cinerea isolates to Fenhexamid}

For the antifungal test, the individual isolates were seeded in the PDA agar seven days before the test until sporulation. This determination was developed in a 96well plate with successive dilutions, after following the methodology previously proposed by (MENDES et al. 2016; TROSKIE et al. 2012), with slight modifications.

To perform this task, $200 \mu \mathrm{L}$ of Fenhexamid was placed in the first column at a concentration of $150 \mathrm{ppm}$. Then, $200 \mu \mathrm{L}$ of sterile YMG broth was poured into the rest of the plate (columns 2-12). Subsequently, the microdilution of the samples was continued. For this process, $100 \mu \mathrm{L}$ of the sample column was taken and, then, deposited in column 2. It was again stirred, and $100 \mu \mathrm{L}$ was taken from this column for deposition in the next column. The process was repeated sequentially until column 10 was filled completely; the excess volume was discarded. Finally, the growth and sterility controls were arranged in the last two columns (11 and 12), respectively. Thus, the concentrations to be evaluated were between $50 \mu \mathrm{g} \mathrm{mL}^{-1}$ and $0.0076 \mu \mathrm{g} \mathrm{mL}^{-1}$ by considering the serial dilutions with a dilution factor of 3 . The optical density was measured immediately after inoculation (zero time) at $595 \mathrm{~nm}$ in a Thermo MultiSkan GO microplate reader. The plate was incubated at $25^{\circ} \mathrm{C}$ for 48 hours, and the optical density was measured again.

Growth control is the value from which the percentage of inhibition exerted by Fenhexamid is calculated.

\section{Statistical analysis}

All morphological and pathogenic characterization analyses were performed by using the Past software (Paleontological Statistics Software Package for Education and Data Analysis) (HAMMER et al. 2001) and InfoStat, which complied with the normality assumptions. Allelic genotyping was obtained by analyzing the polymorphic bands with the GenAlex 6 program (PEAKALL AND SMOUSE, 2006), which estimated the measures of diversity, variability and genetic distance. The cluster analysis was performed by using the UPGMA method, and a dendrogram was generated by using the Dice coefficient with the Past statistical package (HAMMER et al. 2001).

In the Fenhexamid susceptibility tests, the logarithm of the Concentration versus Percentage of Inhibition was plotted based on the obtained data and means of a linear regression. In addition, the value of $x$ was determined in order to make the dependent variable equal to 50 (50\% inhibition). Finally, the $\mathrm{EC}_{50}$ was calculated on the basis of the logarithmic transformation performed on the concentration. 


\section{Results and discussion}

In total, 50 isolates were identified as $B$. cinerea based on the macroscopic and microscopic phenotypic characteristics, such as conidiophores and hyaline conidia, long and abundant gray mycelium, branched conidiophores with rounded apical cells in clusters, colorless or gray, unicellular and with the presence of ovoid conidia. Conidiophores and conidia clusters resembled a bunch of grapes, which was described in previous studies (AGRIOS, 2005; CROUS, 2009; ELLIS, 1971) (Figure 2). Table 1 presents the collection sites and a summary of the morphological, molecular, and pathogenic characteristics.

$B$. cinerea is a species, which shows a great variability in its morphology, sporulation intensity, mycelial growth, enzymatic production, fungicide resistance, along with great genetic diversity (CHARDONNET et al. 2000; LEROUX et al. 2004).

\section{Morphological characterization}

In total, $58.7 \%$ of the isolates reported sparse mycelium, $39.1 \%$ of them reported erumpent mycelium, and $2.2 \%$ showed mass growth (Table 1) (Figure 3 ).

It was possible to observe the three types of mycelial appearance described by Martínez et al. (2003) in the 50 isolates, which correspond to short, aerial, and cottony mycelium. Xie et al. (2016) along with other authors have reported only two types of appearances: woolly and mass mycelial in bean and mustard crops in China. Other authors, such as Nuñez et al. (2013), have only reported a cottony appearance in $B$. cinerea isolates in the cucumber crops from Mexico.

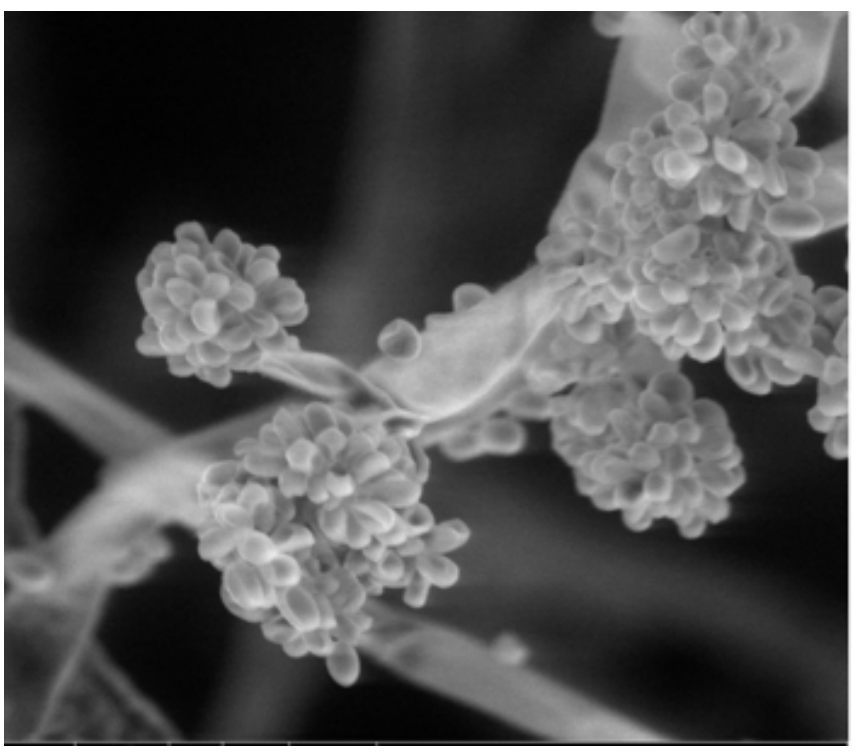

Figure 2. Branched conidiophores with rounded apical cells in clusters of Botrytis cinerea. Image seen with a scanning electron microscope

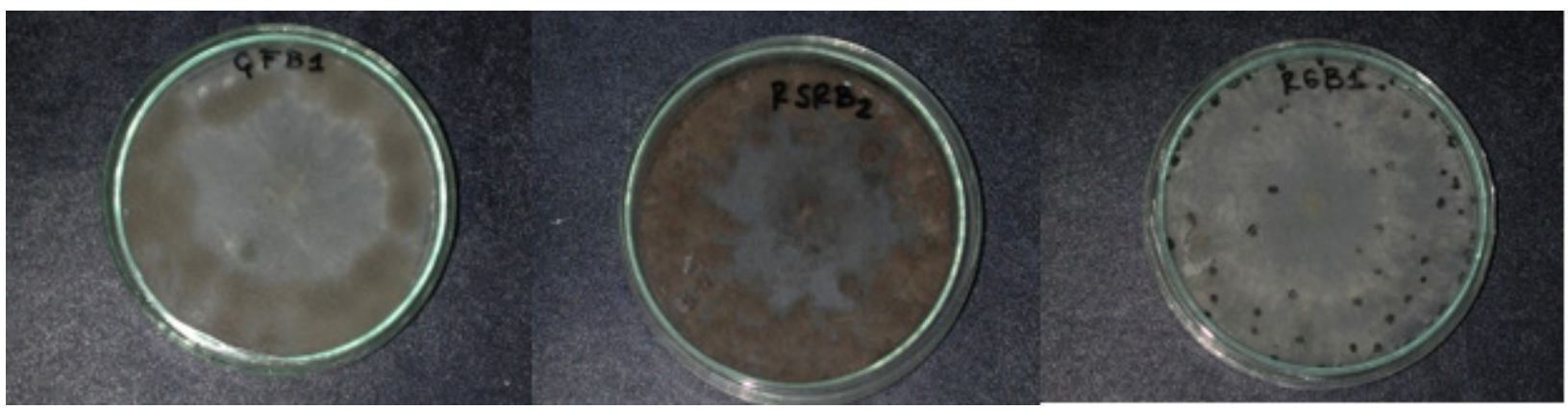

Figure 3. Type of mycelium growth observed in the isolates of Botrytis cinerea. A. Sparse mycelium; B. Erumpent mycelium; C. Mass growth 
Table 1. Identification and the collection place of the $B$. cinerea isolates.

\begin{tabular}{|c|c|c|c|c|c|c|}
\hline Isolates & Department & Georeference & $\begin{array}{c}\text { Sclerotia } \\
\text { distribution }\end{array}$ & $\begin{array}{c}\text { Type of } \\
\text { mycelium }^{\mathrm{b}}\end{array}$ & $\begin{array}{c}\text { Transposable } \\
\text { elements }^{\mathrm{c}}\end{array}$ & $\begin{array}{c}\mathrm{EC} 50 \\
\mu \mathrm{g} / \mathrm{mL}^{\mathrm{d}}\end{array}$ \\
\hline RQB1 & Risaralda/Quinchía1 & $\begin{array}{c}\mathrm{W} 75^{\circ} 45^{\prime} 23,6^{\prime \prime} \\
\mathrm{N} 5^{\circ} 21^{\prime} 12,2^{\prime \prime} 5^{\circ} 21\end{array}$ & E2 & 0 & Vacuma & $\begin{array}{l}<0.1 \\
\text { HysS }\end{array}$ \\
\hline RQB2 & Risaralda/Quinchía2 & $\begin{array}{l}\text { W } 75^{\circ} 45^{\prime} 25,2^{\prime \prime} \\
\text { N } 5^{\circ} 21^{\prime} 14,7^{\prime \prime}\end{array}$ & E4 & 0 & Vacuma & $\begin{array}{l}<0.1 \\
\text { HydS }\end{array}$ \\
\hline RQB3 & Risaralda/Quinchía3 & $\begin{array}{l}\text { W } 75^{\circ} 45^{\prime} 25,2^{\prime \prime} \\
\text { N } 5^{\circ} 21^{\prime} 12,4^{\prime \prime}\end{array}$ & E5 & 1 & Transposa & $\begin{array}{c}0.15 \\
\text { HydR3 }\end{array}$ \\
\hline RGB1 & Risaralda/Guática1 & $\begin{array}{l}\text { W } 75^{\circ} 47^{\prime} 20,7^{\prime \prime} \\
\text { N } 5^{\circ} 17^{\prime} 26,9^{\prime \prime}\end{array}$ & E3 & 0 & Vacuma & $\begin{array}{l}<0.1 \\
\text { HydS }\end{array}$ \\
\hline RGB2 & Risaralda/Guática2 & $\begin{array}{l}\text { W } 75^{\circ} 47^{\prime} 25,9^{\prime \prime} \\
\text { N } 5^{\circ} 17^{\prime} 36,3^{\prime \prime}\end{array}$ & E3 & 0 & Vacuma & $\begin{array}{l}<0.1 \\
\text { HydS }\end{array}$ \\
\hline RGB3 & Risaralda/Guática3 & $\begin{array}{l}\text { W } 75^{\circ} 47^{\prime} 27,1 " \\
\text { N } 5^{\circ} 19^{\prime} 07,0 "\end{array}$ & E4 & 0 & Transposa & $\begin{array}{l}<0.1 \\
\text { HydS }\end{array}$ \\
\hline RBUB1 & Risaralda/Belén de Umbría1 & $\begin{array}{l}\text { W 755 } 54^{\prime} 43,1^{\prime \prime} \\
\text { N } 5^{\circ} 11^{\prime} 10,6^{\prime \prime}\end{array}$ & E3 & 1 & Flipper & $\begin{array}{l}<0.1 \\
\text { HydS }\end{array}$ \\
\hline RBUB2 & Risaralda/Belén de Umbría2 & $\begin{array}{l}\text { W 755 } 54^{\prime} 55,4^{\prime \prime} \\
\text { N } 5^{\circ} 11^{\prime} 05,3^{\prime \prime}\end{array}$ & E3 & 0 & Vacuma & $\begin{array}{l}<0.1 \\
\text { HydS }\end{array}$ \\
\hline RSRB1 & Risaralda/Santa Rosa1 & $\begin{array}{l}\text { W } 75^{\circ} 55^{\prime} 15,7^{\prime \prime} \\
\text { N } 5^{\circ} 11^{\prime} 13,0^{\prime \prime}\end{array}$ & E4 & 1 & Transposa & $\begin{array}{l}<0.1 \\
\text { HydS }\end{array}$ \\
\hline RSRB2 & Risaralda/Santa Rosa2 & $\begin{array}{l}\text { W } 75^{\circ} 33^{\prime} 39,5^{\prime \prime} \\
\text { N } 4^{\circ} 53^{\prime} 19,64^{\prime \prime}\end{array}$ & E5 & 2 & Vacuma & $\begin{array}{c}0.13 \\
\text { HydR3- }\end{array}$ \\
\hline RSRB3 & Risaralda/Santa Rosa3 & $\begin{array}{l}\mathrm{W} 75^{\circ} 33^{\prime} 40,8^{\prime \prime} \\
\mathrm{N} 4^{\circ} 53^{\prime} 15,5^{\prime \prime}\end{array}$ & E3 & 0 & Vacuma & $\begin{array}{l}<0.1 \\
\text { HydS }\end{array}$ \\
\hline RAB1 & Risaralda/Apía1 & $\begin{array}{l}\text { W } 75^{\circ} 33^{\prime} 51,3^{\prime \prime} \\
\text { N } 4^{\circ} 53^{\prime} 11,9^{\prime \prime}\end{array}$ & E5 & 1 & Transposa & $\begin{array}{c}0.2 \\
\text { HydR3- }\end{array}$ \\
\hline RAB2 & Risaralda/Apía2 & $\begin{array}{l}\mathrm{W} 75^{\circ} 59^{\prime} 12,6^{\prime \prime} \\
\mathrm{N} 4^{\circ} 08^{\prime} 0,01 "\end{array}$ & E4 & 1 & Vacuma & $\begin{array}{c}0.2 \\
\text { HydR3- }\end{array}$ \\
\hline RAB3 & Risaralda/Apía3 & $\begin{array}{l}\text { W } 75^{\circ} 59^{\prime} 19,6^{\prime \prime} \\
\text { N } 5^{\circ} 07^{\prime} 59,5^{\prime \prime},\end{array}$ & E4 & 0 & Vacuma & $<0.1$ \\
\hline RSB1 & Risaralda/Santuario1 & $\begin{array}{l}\text { W } 75^{\circ} 59^{\prime} 16,9^{\prime \prime} \\
\text { N } 5^{\circ} 0,08^{\prime} 02,3^{\prime \prime}\end{array}$ & E1 & 1 & Vacuma & $\begin{array}{c}0.2 \\
\text { HydR3- }\end{array}$ \\
\hline RSB3 & Risaralda/Santuario2 & $\begin{array}{l}\text { W 75 } 55^{\circ}, 29,7^{\prime} \\
\text { N } 5^{\circ} 0,6^{\prime} 33,7^{\prime}\end{array}$ & E3 & 0 & Vacuma & $\begin{array}{l}<0.1 \\
\text { HydS }\end{array}$ \\
\hline QGB1 & Quindío/Génova1 & $\begin{array}{l}\text { W 75 } 55^{\circ}, 45,7^{\prime \prime} \\
\text { N } 5^{\circ} 0,6^{\prime} 37,2^{\prime \prime}\end{array}$ & E3 & 0 & Vacuma & $\begin{array}{c}0.2 \\
\text { HydR3- }\end{array}$ \\
\hline QGB2 & Quindío/Génova2 & $\begin{array}{l}\text { W 75 } 45^{\circ} 46^{\prime} 06,6^{\prime \prime} \\
\text { N } 4^{\circ} 16^{\prime} 43,2^{\prime \prime}\end{array}$ & E3 & 1 & Vacuma & $\begin{array}{l}0.15 \\
\text { HydR3- }\end{array}$ \\
\hline QFB1 & Quindío/Filandia1 & $\begin{array}{l}\mathrm{W} 75^{\circ} 46^{\prime} 04,9^{\prime \prime} \\
\mathrm{N} 4^{\circ} 16^{\prime} 40,0^{\prime \prime}\end{array}$ & E1 & 1 & Flipper & $\begin{array}{l}<0.1 \\
\text { HydS }\end{array}$ \\
\hline QFB2 & Quindío/Filandia2 & $\begin{array}{l}\text { W } 75^{\circ} 37^{\prime} 05,4^{\prime \prime} \\
\text { N } 4^{\circ} 41^{\prime} 08,8^{\prime \prime}\end{array}$ & E3 & 0 & Vacuma & $\begin{array}{l}<0.1 \\
\text { HydS }\end{array}$ \\
\hline QCB1 & Quindío/Córdoba1 & $\begin{array}{l}\text { W } 75^{\circ} 37^{\prime} 01,8^{\prime \prime} \\
\text { N } 4^{\circ} 41^{\prime} 12,11^{\prime \prime}\end{array}$ & E3 & 0 & Vacuma & $\begin{array}{l}<0.1 \\
\text { HydS }\end{array}$ \\
\hline QCB2 & Quindío/Córdoba2 & $\begin{array}{l}\text { W } 75^{\circ} 39^{\prime} 18,1^{\prime \prime} \\
\text { N } 4^{\circ} 24^{\prime} 0,08^{\prime \prime}\end{array}$ & E3 & 1 & Vacuma & $\begin{array}{l}<0.1 \\
\text { HydS }\end{array}$ \\
\hline CVB1 & Caldas/Villamaría1 & $\begin{array}{l}\mathrm{W} 75^{\circ} 39^{\prime} 13,9^{\prime \prime} \\
\mathrm{N} 4^{\circ} 24^{\prime} 04,2^{\prime \prime}\end{array}$ & E2 & 1 & Flipper & $\begin{array}{l}<0.1 \\
\text { HydS }\end{array}$ \\
\hline CVB2 & Caldas/Villamaría2 & $\begin{array}{l}\mathrm{W} 75^{\circ} 29^{\prime} 39,1^{\prime \prime} \\
\mathrm{N} 4^{\circ} 58^{\prime} 00,1^{\prime \prime}\end{array}$ & E1 & 1 & Flipper & $\begin{array}{c}<0.1 \\
\text { HydS }\end{array}$ \\
\hline CAB1 & Caldas/Aguadas1 & $\begin{array}{l}\text { W } 75^{\circ} 29^{\prime} 46,0^{\prime \prime} \\
\text { N } 4^{\circ} 57^{\prime} 26,8^{\prime \prime}\end{array}$ & E5 & 1 & Transposa & $\begin{array}{c}1.3 \\
\text { HydR3- }\end{array}$ \\
\hline CAB2 & Caldas/Aguadas2 & $\begin{array}{l}\text { W } 75^{\circ} 27^{\prime} 27,3^{\prime \prime} \\
\text { N } 5^{\circ} 34^{\prime} 19,1 "\end{array}$ & E5 & 1 & Transposa & $\begin{array}{l}0.13 \\
\text { HydR3- }\end{array}$ \\
\hline CAB3 & Caldas/Aguadas3 & $\begin{array}{l}\text { W } 75^{\circ} 27^{\prime} 30,8^{\prime \prime} \\
\text { N } 5^{\circ} 35^{\prime} 00,0 "\end{array}$ & E5 & 1 & Vacuma & $\begin{array}{c}0.12 \\
\text { HydR3- }\end{array}$ \\
\hline CPB1 & Caldas/Pácora1 & $\begin{array}{l}\text { W } 75^{\circ} 27^{\prime} 18,0^{\prime \prime} \\
\text { N } 5^{\circ} 35^{\prime} 21,8^{\prime \prime}\end{array}$ & E3 & 0 & Vacuma & ND \\
\hline CPB2 & Caldas/Pácora2 & $\begin{array}{l}\text { W 752 } 27^{\prime} 48,8^{\prime \prime} \\
\text { N } 5^{\circ} 30^{\prime} 32,5^{\prime \prime}\end{array}$ & E3 & 1 & Vacuma & $\begin{array}{l}<0.1 \\
\text { HydS }\end{array}$ \\
\hline CUSB1 & Cundinamarca/Silvania1 & ND & E3 & 0 & Vacuma & $\begin{array}{c}<0.1 \\
\text { HydS }\end{array}$ \\
\hline
\end{tabular}




\begin{tabular}{|c|c|c|c|c|c|c|}
\hline CUSB2 & Cundinamarca/Silvania2 & $\begin{array}{l}\text { W 74 } 19^{\prime} 32,6^{\prime \prime} \\
\text { N } 4^{\circ} 24^{\prime} 21,0^{\prime \prime}\end{array}$ & E3 & 0 & Vacuma & $\begin{array}{l}<0.1 \\
\text { HydS }\end{array}$ \\
\hline CUSB3 & Cundinamarca/Silvania3 & $\begin{array}{l}\text { W } 74^{\circ} 19^{\prime} 44,5^{\prime \prime} \\
\text { N } 4^{\circ} 25^{\prime} 01,3^{\prime \prime}\end{array}$ & E3 & 0 & Boty & $\begin{array}{l}<0.1 \\
\text { HydS }\end{array}$ \\
\hline CUSBB3 & Cundinamarca/San Bernardo3 & $\begin{array}{l}\text { W } 74^{\circ} 19^{\prime} 51,33^{\prime \prime} \\
\text { N } 4^{\circ} 25^{\prime} 40,3, "\end{array}$ & E3 & 0 & Vacuma & $\begin{array}{l}<0.1 \\
\text { HydS }\end{array}$ \\
\hline CUFB1 & Cundinamarca/Fusagasugá1 & $\begin{array}{l}\text { W } 74^{\circ} 23^{\prime} 0,72^{\prime \prime} \\
\text { N } 4^{\circ} 08^{\prime} 58,3^{\prime \prime}\end{array}$ & E3 & 1 & Vacuma & ND \\
\hline CUFB2 & Cundinamarca/Fusagasugá2 & $\begin{array}{l}\text { W } 74^{\circ} 21^{\prime} 20,7^{\prime \prime} \\
\text { N } 4^{\circ} 17^{\prime} 05,2^{\prime \prime}\end{array}$ & E4 & 0 & Vacuma & $\begin{array}{l}<0.1 \\
\text { HydS }\end{array}$ \\
\hline CUFB3 & Cundinamarca/Fusagasugá3 & $\begin{array}{l}\mathrm{W} 74^{\circ} 21^{\prime} 26,0^{\prime \prime} \\
\mathrm{N} 4^{\circ} 15^{\prime} 42,1\end{array}$ & E4 & 0 & Vacuma & $\begin{array}{l}<0.1 \\
\text { HydS }\end{array}$ \\
\hline SPB1 & Santander/Pie de cuesta1 & $\begin{array}{l}\text { W } 74^{\circ} 21^{\prime} 04,2^{\prime \prime} \\
\text { N } 4^{\circ} 14^{\prime} 35,6^{\prime \prime}\end{array}$ & E4 & 1 & Vacuma & $\begin{array}{c}0.12 \\
\text { HydR3- }\end{array}$ \\
\hline SPB3 & Santander/Pie de cuesta3 & $\begin{array}{l}\text { W } 72^{\circ} 58^{\prime} 50,1^{\prime \prime} \\
\text { N } 7^{\circ} 00^{\prime} 31,6^{\prime \prime}\end{array}$ & E4 & 0 & Vacuma & $\begin{array}{l}<0.1 \\
\text { HydS }\end{array}$ \\
\hline TCB1 & Tolima/Cajamarca1 & $\begin{array}{l}\text { W } 72^{\circ} 59^{\prime} 46,8^{\prime \prime} \\
\text { N } 6^{\circ} 59^{\prime} 06,3 \prime\end{array}$ & E3 & 0 & Flipper & $\begin{array}{l}<0.1 \\
\text { HydS }\end{array}$ \\
\hline TCB2 & Tolima/Cajamarca2 & $\begin{array}{l}\text { W } 75^{\circ} 30^{\prime} 03,0^{\prime \prime} \\
\text { N } 4^{\circ} 22^{\prime} 13,4^{\prime \prime}\end{array}$ & E3 & 0 & Vacuma & $\begin{array}{l}<0.1 \\
\text { HydS }\end{array}$ \\
\hline TCB3 & Tolima/Cajamarca3 & $\begin{array}{l}\text { W } 75^{\circ} 29^{\prime} 50,4^{\prime \prime} \\
\text { N } 4^{\circ} 22^{\prime} 29,9^{\prime}\end{array}$ & E3 & 0 & Vacuma & $\begin{array}{c}0.2 \\
\text { HydR3- }\end{array}$ \\
\hline ACB1 & Antioquia/La ceja1 & $\begin{array}{l}\text { W } 75^{\circ} 29^{\prime} 26,4^{\prime \prime} \\
\text { N } 4^{\circ} 22^{\prime} 29,99^{\prime \prime}\end{array}$ & E4 & 0 & Flipper & $\begin{array}{c}0.5 \\
\text { HydR3- }\end{array}$ \\
\hline AEB1 & Antioquia/Envigado1 & $\begin{array}{l}\text { W } 75^{\circ} 26^{\prime} 44,7^{\prime \prime} \\
\text { N } 5^{\circ} 58^{\prime} 53,1^{\prime \prime}\end{array}$ & E5 & 1 & Transposa & $\begin{array}{l}<0.1 \\
\text { HydS }\end{array}$ \\
\hline AEB2 & Antioquia/Envigado2 & $\begin{array}{l}\text { W } 75^{\circ} 29^{\prime} 26,3^{\prime \prime} \\
\text { N } 6^{\circ} 10^{\prime} 56,0^{\prime \prime}\end{array}$ & E1 & 1 & Transposa & $\begin{array}{l}<0.1 \\
\text { HydS }\end{array}$ \\
\hline AEB3 & Antioquia/Envigado3 & $\begin{array}{l}\mathrm{W} 75^{\circ} 29^{\prime} 28,3^{\prime \prime} \\
\mathrm{N} 6^{\circ} 10^{\prime} 31,8^{\prime \prime}\end{array}$ & E3 & 0 & Transposa & $\begin{array}{l}<0.1 \\
\text { HydS }\end{array}$ \\
\hline AGB1 & Antioquia/Guarne1 & $\begin{array}{l}\mathrm{W} 75^{\circ} 29^{\prime} 27,8^{\prime \prime} \\
\mathrm{N} 6^{\circ} 10^{\prime} 32,1^{\prime \prime}\end{array}$ & E3 & 1 & Flipper & $\begin{array}{l}<0.1 \\
\text { HydS }\end{array}$ \\
\hline AGB2 & Antioquia/Guarne2 & ND & E4 & 1 & Flipper & $\begin{array}{l}<0.1 \\
\text { HydS }\end{array}$ \\
\hline AGB3 & Antioquia/Guarne3 & $\begin{array}{l}\text { W } 75^{\circ} 24^{\prime} 49,7^{\prime \prime} \\
\text { N } 6^{\circ} 16^{\prime} 35,4^{\prime \prime}\end{array}$ & E3 & 0 & Flipper & $\begin{array}{l}<0.1 \\
\text { HydS }\end{array}$ \\
\hline VGB1 & Valle del Cauca/Ginebra1 & $\begin{array}{l}\text { W } 75^{\circ} 24^{\prime} 59,1^{\prime \prime} \\
\text { N } 6^{\circ} 16^{\prime} 37,5^{\prime \prime}\end{array}$ & E4 & 0 & Vacuma & $\begin{array}{l}<0.1 \\
\text { HydS }\end{array}$ \\
\hline VGB2 & Valle del Cauca/Ginebra2 & $\begin{array}{l}\text { W } 76^{\circ} 12^{\prime} 15,1 " \\
\text { N } 3^{\circ} 16^{\prime} 50,8^{\prime \prime}\end{array}$ & E5 & 1 & Flipper & $\begin{array}{c}0.14 \\
\text { HydR3- }\end{array}$ \\
\hline
\end{tabular}

${ }^{\mathrm{a}} \mathrm{E} 1$ = sclerotia only on the edge, E2 = sclerotia arranged radially, E3 = large and irregularly distributed sclerotia, E4 = numerous and scattered small sclerotia and E5 = no sclerotia.

${ }^{\mathrm{b}} 0=$ sparse mycelium, $1=$ erumpent mycelium and $2=$ mycelium with mass growth

${ }^{\mathrm{c}}$ Transposa $=$ strain with the two Boty and Flipper transposable elements present, Vacuma $=$ strain that lacks the two transposable elements, Flipper $=$ strain with only the Flipper transposable element, and Boty $=$ strain with only the Boty transposable element.

${ }^{d}$ Values of $\mathrm{EC}_{50}<0.1$ correspond to strains susceptible to Fenhexamid (HydS) and values of $\mathrm{EC}_{50}>0.1$ and $<3$ correspond to strains moderately resistant to Fenhexamid (HydR3).

Statistically significant differences were observed in the growth of the fungus cultured in PDA agar. The isolates from Guarne (Antioquia) were the reported to be the fastest growing; their growth was registered on the third day. Their horizontal and vertical growths were reported to have average values of $74.4 \mathrm{~mm}$ and $73.7 \mathrm{~mm}$, respectively, whereas the QCB1 isolates grew the slowest, with average values of $23 \mathrm{~mm}$ and $24.7 \mathrm{~mm}$ (horizontal and vertical). Tanović et al. (2009) reported growth rates from the third day ranging from $7.3 \mathrm{~mm}$ to $26.7 \mathrm{~mm} /$ day by using the same culture medium. Other authors, such as Chardonnet et al. (2000) and Mirzaei et al. (2008), also reported heterogeneities in the growth rates of B. cinerea. We also observed that the second and third days reported the highest growth rates. 

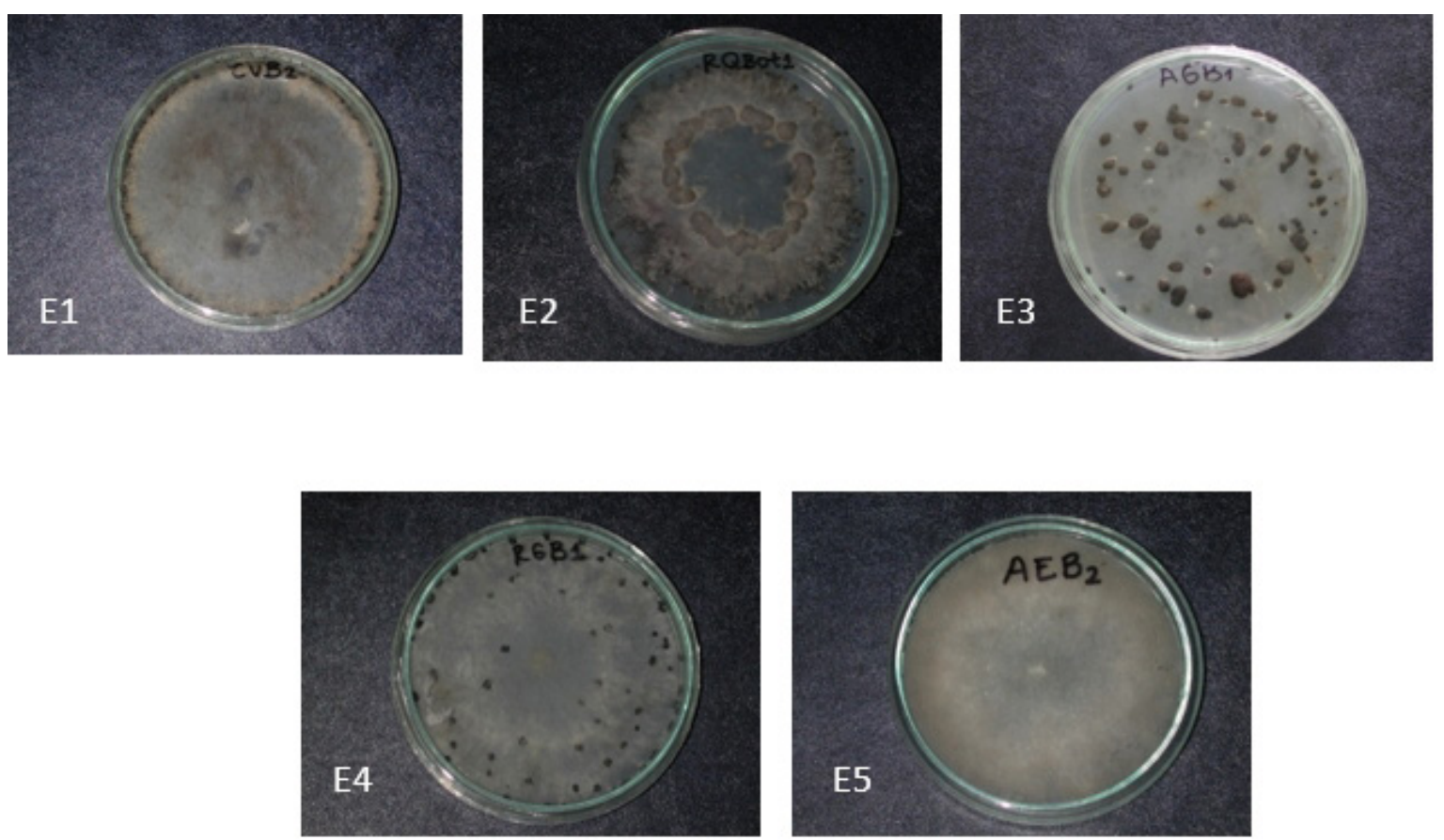

Figure 4. The distribution of sclerotia observed in the Botrytis cinerea isolates

Regarding the distribution of sclerotia, $43 \%$ of the isolates showed randomly distributed large sclerotia (E3), $22 \%$ showed randomly distributed small sclerotia (E4), and the same percentage (22\%) of isolates did not show sclerotia (E5). $7 \%$ of the isolates had an E1 classification corresponding to sclerotia, which was arranged only at the edge of the petri dish. On the contrary, $3 \%$ of the studied isolates showed radially distributed sclerotia (E2) (Figure 4).

Martínez et al. (2003) reported the distributions of random sclerotia in circles or on the edge of the petri dish, whereas Tanović et al. (2009) refered to mycelial and sclerocial growths, which depended on the absence or presence of sclerotia. These researchers reported that $38.7 \%$ of the isolates lack sclerotia. However, in our investigation, $22 \%$ of the isolates corresponded to category E5 (no sclerotia). Sclerotia are considered to be the most important structures for fungal survival (Botrytis spp). All Botrytis species form sclerotia, which can vary in size and shape depending on the host and environmental conditions. The production, size, and shape of sclerotia in a natural substrate is extremely fluctuating unlike a culture medium. Due to this reason, some isolates of the fungus do not form sclerotia, whereas others abundantly produce sclerotia (AGRIOS, 1988).

Regarding the size of the sclerotia, we find that for a value of $p=0.0001$, the ANOVA analysis suggests that the hypothesis of equality of means between the isolates is rejected. According to Fisher's LSD test, there are statistically significant differences between the different groups; the isolates of CUSBB3, RQB1, QGB2, RSB3, TCB3, and QGB1 have shown sclerotia of larger sizes. The RAB2 isolate showed the smallest sclerotia with an average of $1.5 \times 1.53 \mathrm{~mm}$ and the largest with the value of $5.93 \times 4.58 \mathrm{~mm}$ were found in the CUSBB3 isolate.

Using the RAL color chart as a reference, the colors shown in all of the isolates are gray and brown in different shades, with gray tones being the most predominant. All of the isolates showed shades described by B. cinerea, which is initially whitish. Later, different shades of gray and brown were also shown (KHAZAELI et al. 2010; XIE et al. 2016).

\section{Genetic characterization}

Analysis of microsatellite molecular markers

The genetic characterization of the B. cinerea isolates performed with nine pairs of primers obtained an amplification of 12 loci. The population with the highest number of alleles was Risaralda (8.083), whereas Santander showed the lowest number of alleles. The expected heterozygosity $(\mathrm{He})$ was also higher in Risaralda $(0.808)$, followed by the Caldas population $(0.764)$. The lowest heterozygosities were registered in the departments of Santander and Valle (Table 2).

The populations of $B$. cinerea have remarkable levels of genetic diversity. Rajaguru and Shaw (2010) analyzed nine microsatellite loci in the strains of B. cinerea isolated from four plant genera in Southern England and concluded that the isolated strains from strawberries were very different from the isolated blackberry strains. However, both hosts belong to the rosacea family, and their mechanisms of infection and fruit ripening are similar, which could suggest that disease cycles in the separate hosts in the same region may be weakly linked. By using the same microsatellites, Karchani et al. (2008) concluded that the population of this fungus in Tunisia reproduces 
mainly through sexual reproduction. In this investigation, only one host (the Andean blackberry) was studied and the form of reproduction was not contemplated.

The populations of $B$. cinerea have remarkable levels of genetic diversity. Rajaguru and Shaw (2010) analyzed nine microsatellite loci in the strains of $B$. cinerea isolated from four plant genera in Southern England and concluded that the isolated strains from strawberries were very different from the isolated blackberry strains.
However, both hosts belong to the rosacea family, and their mechanisms of infection and fruit ripening are similar, which could suggest that disease cycles in the separate hosts in the same region may be weakly linked. By using the same microsatellites, Karchani et al. (2008) concluded that the population of this fungus in Tunisia reproduces mainly through sexual reproduction. In this investigation, only one host (the Andean blackberry) was studied and the form of reproduction was not contemplated.

Table 2. Parameters of genetic diversity in Botrytis cinerea isolates.

\begin{tabular}{|c|c|c|c|c|c|c|c|c|}
\hline Parameter & Risaralda & Quindío & $\begin{array}{c}\text { Caldas/ } \\
\text { Villamaría1 }\end{array}$ & Cundimamarca & Santander & Tolima & Antioquia & Valle \\
\hline $\begin{array}{l}\text { Number of } \\
\text { alleles }(\mathrm{Na})\end{array}$ & $\begin{array}{c}8,083 \pm \\
0,645\end{array}$ & $\begin{array}{c}4,583 \pm \\
0,336\end{array}$ & $\begin{array}{c}5,333 \pm \\
0,284\end{array}$ & $\begin{array}{c}5,250 \pm \\
0,479\end{array}$ & $\begin{array}{c}2,917 \pm \\
0,260\end{array}$ & $\begin{array}{c}3,500 \pm \\
0,337\end{array}$ & $\begin{array}{c}5,333 \pm \\
0,333\end{array}$ & $\begin{array}{r}3,000 \pm \\
0,246\end{array}$ \\
\hline $\begin{array}{l}\text { Number of } \\
\text { effective alleles } \\
(\mathrm{Ne})\end{array}$ & $\begin{array}{c}5,708 \pm \\
0,514\end{array}$ & $\begin{array}{c}3,464 \pm \\
0,194\end{array}$ & $\begin{array}{c}4,368 \pm \\
0,233\end{array}$ & $\begin{array}{c}4,028 \pm \\
0,316\end{array}$ & $\begin{array}{c}1,011 \pm \\
0,261\end{array}$ & $\begin{array}{c}3,168 \pm \\
0,289\end{array}$ & $\begin{array}{c}3,795 \pm \\
0,294\end{array}$ & $\begin{array}{c}2,856 \pm \\
0,263\end{array}$ \\
\hline $\begin{array}{c}\text { Expected } \\
\text { heterozygosity }\end{array}$ & $\begin{array}{c}0,808 \pm \\
0,017\end{array}$ & $\begin{array}{c}0,702 \pm \\
0,016\end{array}$ & $\begin{array}{c}0,764 \pm \\
0,011\end{array}$ & $\begin{array}{c}0,734 \pm \\
0,021\end{array}$ & $\begin{array}{c}0,615 \pm \\
0,032\end{array}$ & $\begin{array}{c}0,653 \pm \\
0,032\end{array}$ & $\begin{array}{c}0,716 \pm \\
0,025\end{array}$ & $\begin{array}{r}0,615 \pm \\
0,036\end{array}$ \\
\hline
\end{tabular}

The ANOVA analysis (Table 3) allows for the identification of the greatest variability that exists within each population with $84 \%$ variation and, to a lesser extent, between populations (16\%). By using nine microsatellite markers, Isenegger et al. (2008) studied the genetic diversity of $B$. cinerea in Bangladesh and concluded, as in this research, that genetic diversity is concentrated within populations and there is a little difference between populations in different regions.

In the case of Colombia, there are two significant geographical barriers (the bifurcation of the Andes mountain range) that separate the sampling sites, which would allow us to infer that the geographical factor did not impose a specific level of structuring in $B$. cinerea, with larger barriers perhaps necessary to observe the differentiation between populations. Isenegger et al. (2008) found that genetic differentiation between the regions of Southern Asia and Australia has indicated that geographical barriers and possible events of founder or bottleneck effects have played a significant role in the genetic differentiation between the $B$. cinerea populations of these regions. This could have implications for disease management strategies based on the host resistance between these regions (PANDE et al. 2006). Walker (2016) stated that, in microsatellite studies, indexes of differentiation or analysis, the hosts are recognized as the most powerful structuring factor for the populations of Botrytis sp, rather than geography. In that sense, populations collected from the same host in distant regions may be more genetically similar than the populations collected from different hosts within the same region.

Table 3. ANOVA analysis of Colombian Botrytis cinerea isolates.

\begin{tabular}{cccccc}
\hline Molecular variance & $\begin{array}{c}\text { Degrees of } \\
\text { freedom }\end{array}$ & $\begin{array}{c}\text { Sum of } \\
\text { squares }\end{array}$ & $\begin{array}{c}\text { Mean } \\
\text { Squares }\end{array}$ & $\begin{array}{c}\text { Statistical } \\
\text { variation }\end{array}$ & Percentage \\
\hline Between populations & 7 & 123,586 & 17,655 & 1,592 & $16 \%$ \\
Within populations & 42 & 351,134 & 8,360 & 8,360 & $84 \%$ \\
Total & 49 & 474,720 & & 9,952 & $100 \%$ \\
\hline
\end{tabular}


For the nine microsatellites used in this study, it was found that the number of different alleles $(\mathrm{Na})$ ranged from four to seven (Table 3). Rasiukevičiūtè et al. (2018) reported between 9 and 23 alleles by using four markers $(\mathrm{Bc} 2, \mathrm{Bc} 6, \mathrm{Bc} 7$, and Bc10) with an average of 13.25 alleles per marker. Fournier and Giraud (2008) found between 3 and 6 alleles per marker as observed in this investigation. The heterozygosities observed for loci Bc1, Bc2, Bc4-1, and $\mathrm{Bc} 10-1$ provided values of 1 , thereby indicating that all the isolates collected were heterozygous for these markers.
Walker (2016) reported that a single allele of 86-bp in the Bc6 locus serves as a diagnostic tool for determining B. cinerea Group I. In this study, none of the isolates were presented with this allele; therefore, we can infer that all of the samples belong to $B$. cinerea Group II.

The main coordinate analysis (Figure 5) shows a tendency for the isolates to be grouped by the geographical area. A large group conforms to the majority of the coffee axis isolates (Caldas, Quindío, and Risaralda), whereas another group conforms to the isolates from Santander, Antioquia, and Tolima. In addition, a small group presents the place where most of the Cundinamarca isolates are found.

\section{Principal Coordinates (PCoA)}

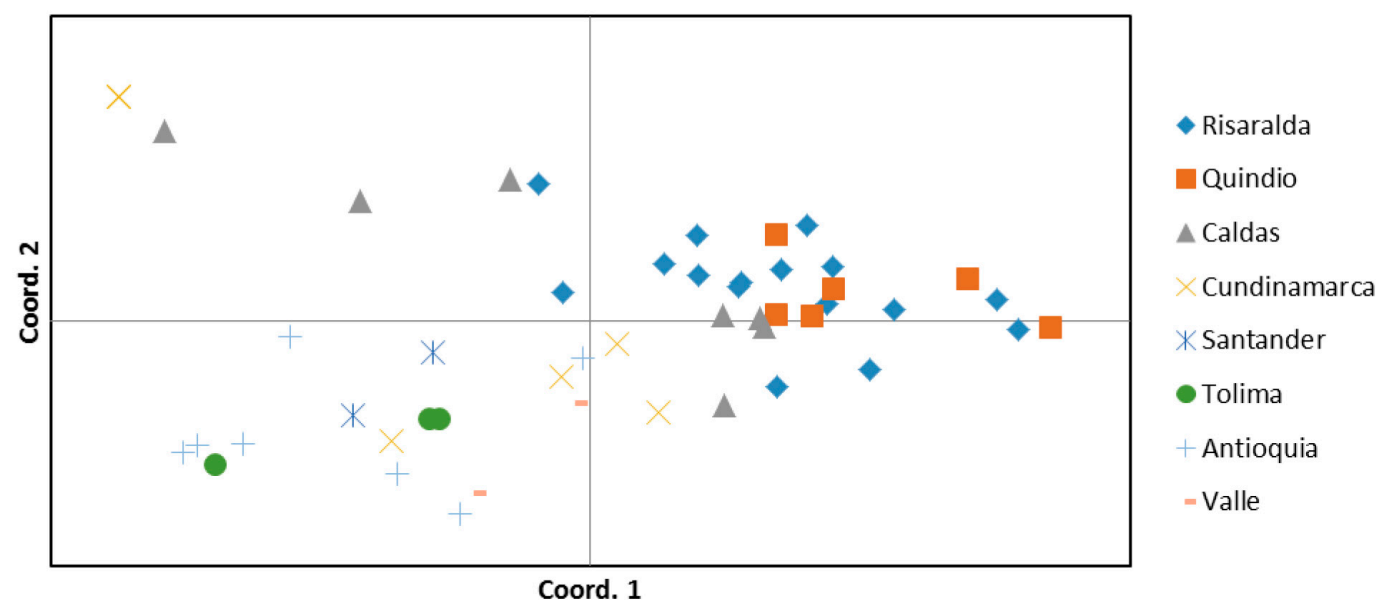

Figure 5. Analysis of the main coordinates of Botrytis cinerea isolates

\section{isolates}

Evaluation of the pathogenicity of $B$. cinerea

The results of the pathogenicity tests show us that a value of $\mathrm{p}=0.0001$ in the ANOVA suggests that there are statistically significant differences between the isolates, with RQB3 and CUSB3 being the most pathogenic. On the fourth day of inoculation, both isolates reached Level 4 on the severity scale. Similar results were obtained by Núñez et al. (2013), who conducted tests on cucumber fruits that showed the symptoms of dark gray rot and abundant fungus sporulation on the sixth day after inoculation of the fruits. On the contrary, Li et al. (2016) reported that symptoms of the disease were apparent from the third day of the inoculation of Botrytis cinerea in beans.

The RQB3 isolation belongs to the Transposa genotype and has a mycelium with erumpent growth and no sclerotia-forming capacity, whereas CUSB3 is the only one of the isolates found in this research that has a Boty genotype. It has erumpent mycelial growth and has large and irregularly distributed sclerotia. With this observation, we can show that there are no direct relationships between morphological and pathogenic characteristics. B. cinerea shows a high degree of diversity, thereby making it the species where it is difficult to establish relationships between pathogenicity and other characteristics (REBORDINOS et al. 2000).

Determination of the presence/absence of Boty and Flipper transposons in B. cinerea isolates

Fungi possess a variety of extrachromosomal genetic elements such as mitochondrial chromosomes, plasmids, and transposable elements (ROSEWICH AND KISTLER, 2000). One of the reasons for the variations in population dynamics in $B$. cinerea is the presence of mobile elements called transposons (ELAD et al. 2007). Based on the presence or absence of the Boty and Flipper transposable elements, we were able to ascertain that there were four possible types of genotypes in the population of Botrytis cinerea. Transposa (with the presence of the two elements), Vacuma (without the presence of these elements), Boty or Flipper (only one of the two elements present). Therefore, $58 \%$ of the studied isolates belong to Vacuma, 22\% to Flipper, $18 \%$ to Transposa, and only $2 \%$ correspond to Boty. Li et al. (2016) reported that all of the isolates studied in China belong to the Transposa genotype, whereas Isenegger et al. (2008) reported the types of transposons for Bangladesh: $69 \%$ were only Flipper, 24\% Transposa, 2\% were only Boty, and 1\% 
Vacuma. For India/Nepal, 72\% were Boty, 22\% were Flipper, 6\% were Transposa, and 0\% were Vacuma. Kumari et al. (2014) reported the following distribution frequencies in India: 49\% Boty, 23\% Transposa, 15\% Flipper, and 13\% Vacuma. These authors also determined that the distribution of transposable elements have different characteristics, by considering the hosts and geographical location. For example, in Northern India, there are four types of genotypes, whereas in the center of Nepal, they only found Boty genotypes. As for the hosts, the $33 \%$ of chrysanthemum isolates had Transposa and Vacuma, whereas $17 \%$ of chrysanthemum isolates had Boty and Flipper. In lentils, the Flipper and Transposa genotypes were not found. All strawberry isolates belonged to the Boty molecular type, whereas in roses, the Transposa isolate was found most often, followed by Boty and Flipper, with the absence of Vacuma. Studies with transposable elements have shown that the Transposa genotype predominates in the populations of grapes, strawberries, and tomatoes, whereas Vacuma dominates in the populations of kiwi (fruit) and apples (ESTERIO et al. 2011; JOHNSTON et al. 2013; MARTINEZ et al. 2005; SAMUEL et al. 2012). However, there is presently no clear explanation for these observations (WALKER, 2016)

This investigation, which was carried out in the area known as the Colombian Andean region, found four types of genotypes in a single host - the Andean blackberry or the Mora de Castilla. This result is of the utmost importance for the adequate management of the crops. By considering the studies carried out in vineyards and on other crops, the Transposa genotype is characterized as being more stable and homogeneous and presents with a more parasitic character than the Vacuma genotype. Vacuma is less stable and has a more saprophytic character. In Chile, it has been detected in plants that are not subjected to high fungicide pressure. On the contrary, Boty is present in a smaller proportion than the first two, but it occurs in plants subjected to higher fungicide pressure (ESTERIO et al. 2007). In addition, it has been determined that Botrytis genotypes would have a differential sensitivity response to some botryticides. For example, only the Transposa and Flipper isolates have some level of resistance to Iprodione (dicarboximide), whereas Vacuma and Boty have always been sensitive to this fungicide (GIRAUD et al. 1999; ESTERIO, 2005). In relation to anilinopyrimidines (Pyrimethanil, Cyprodinil) and carboxamides (Boscalid), partial results do not yet indicate a marked differential effect toward a certain genotype (ESTERIO et al. 2006).

\section{Determination of the susceptibility of $B$. cinerea isolates to Fenhexamid}

Fenhexamid is a widely used fungicide globally for the control of Botrytis. It is a sterol biosynthesis inhibitor used in the control of gray mold disease. Studies have reported that gray mold disease is caused by a complex of two sympatric species: Botrytis Group II (Botrytis cinerea sensus stricto) and Botrytis Group I (Botrytis pseudocinerea) (FOURNIER, et al. 2005). Suty et al. (1999) reported that the latter metabolizes Fenhexamid more quickly than Botrytis cinerea. The natural resistance of fungus to Fenhexamid is associated with mutations in the erg27 gene that codes for the enzyme 3-keto reductase (ALBERTINI AND LEROUX, 2004; FILLINGER et al. 2008). The fungus' resistance to Fenexhamid has been classified into categories: HydS (Fenhexamid sensitive) HydR1, HydR2 and HydR3 (resistant to Fenhexamid) (ALBERTINI AND LEROUX, 2004; LEROUX, 2004). HydR3 was subdivided into HydR3 + and HydR3- by Fillinger et al. (2008). One of the ways to evaluate this classification is by taking into account the $\mathrm{EC}_{50}$ of germination and tube elongation and mycelial growth in vitro. With our methodology, $\mathrm{EC}_{50}$ values allowed us to classify the isolates as HydS with $\mathrm{EC}_{50}<0.1 \mu \mathrm{g} / \mathrm{mL}$ and HydR3- isolates with $\mathrm{EC}_{50}$ between $>0.1$ and $<3 \mu \mathrm{g} / \mathrm{mL}$ (FILLINGER, et al. 2008).

In total, $68 \%$ of the isolates studied are susceptible to Fenhexamid (HydS) and $34 \%$ have a moderate resistance to the fungicide (HydR3-) (Table 1). In the first group (HydS), we found 20 isolates of the Vacuma genotype, 8 Flipper, 5 Transposa, and the only Boty genotype was reported in this investigation. In the isolates with intermediate resistance to Fenhexamid (HydR3-), we found eight of the Vacuma type, four of Transposa type, and two of Flipper. Albertini and Leroux (2004) reported that only the Vacuma and Transposa genotypes were susceptible isolates (HydS), and only Transposa genotypes (HydR2 and HydR3) were resistant isolates. As already mentioned, there are different characteristics, such as hosts, geographical position, seasonal periods and submission to fungicides, that are related to the transposable elements (ISENEGGER et al. 2008; ESTERIO et al. 2007; LI et al. 2016). In addition, it is important to bear in mind that this study was carried out in a tropical area, where optimal conditions for the survival and reproduction of fungi are present due to temperature stability, permanent water availability, the presence of wind, and so on, which can greatly affect the variability of these types of microorganisms.

\section{Conclusion}

In this investigation, it was possible to show the great morphological, genetic, and pathogenic diversities that $B$. cinerea depicts in the Andean blackberry crops in Colombia. This high degree of diversity makes it difficult to establish relationships between the characteristics that allow the management strategies to be established. However, it can be determined that high resistance to 
the fungicide Fenhexamid is not present in the studied isolates. Although the four possible genotypes found had transposable elements, the two types of growth (mycelial and sclerocial) had different sclerotia layouts and size, as well as differentiated mycelium growths. From a microsatellite genetic point of view, it was possible to establish that genetic diversity is concentrated within populations and that there is a little difference between the populations of different regions. In addition, there is a tendency for isolates to be grouped by geographical origin, especially in the two large coffee axis groups: Risaralda, Quindío and Caldas, and Santander, Antioquia and Tolima.

\section{Acknowledgements}

The authors express their gratitude to the Universidad Tecnológica de Pereira (Colombia), and to the General System of Royalties (SGR) (National Planning Department), for financing the research program "Development of scientific and technological capacities in biotechnology applied to the sectors of health and agribusiness in the department of Risaralda", identified by the code BPIN 2012000100050.

\section{References}

AGRIOS, G. Plant pathology. $3^{\text {rd }}$ ed. San Diego: Academic Press, 1988. 845 p.

AGRIOS, G. Plant pathology. $5^{\text {th }}$ ed. London: Academics Press, 2005. $952 \mathrm{p}$.

ALBERTINI, C.; LEROUX, P. A. Botrytis cinerea putative 3-ketoreductase gene (ERG27) that is homologous to the mammalian 17-beta-hydroxysteriod dehydrogenase type 7 gene. European Journal of Plant Pathology, Dordrecht, v.110, p.723-733, 2004.

ALVAREZ, A.; SILVA, H.V. ; LEYVA, S.G.; MARBAN, N.; REBOLLAR, A. Resistance of Botrytis cinerea from strawberry (Fragaria $\mathrm{x}$ ananassa Duch.) to fungicides in Michoacan Mexico. Agrociencia, Chapingo, v.51, n.7, p.783-798, 2017.

BEEVER, R.E.; WEEDS, P.L. Taxonomy and genetic variation of Botrytis and Botryotinia. In: ELAD, Y.; WILLIAMSON, B.; TUDZYNSKI, P.; DELEN, N. (ed.). Botrytis: biology, pathology and contro. Dordrecht: Springer, 2007. cap.3, p.29-52.

BENBOUZA, H.; JACQUEMIN, J.M.; BAUDOIN, J.P.; MERGEAI, G. Optimization of a reliable, fast, cheap and sensitive silver staining method to detect SSR markers in polyacrylamide gels. Biotechnologie, Agronomie, Société et Environment, Gembloux, v.10, n.2, p. 77-81, 2006.
BOTERO, M.J.; FRANCO, G. Identificación y caracterización preliminar del agente causal de la mancha necrótica de las hojas de la mora (Rubus glaucus) en el muncipio de Trujillo (Valle del Cauca, Colombia). Ciencia y Tecnología Agropecuaria, Guatemala, v.8, n.2, p.22-25, 2007.

CASTELLANOS, G.; JARA, C.; MOSQUERA, G. Guías prácticas de laboratorio para el manejo de patogenos del frijol. Cali: Centro Internacional de Agricultura Tropical, 2011. 232p. Disponível em: www.ciat.cgiar. org.20100. Acesso em: 01 feb. 2019.

CHARDONNET, C.; SAMS, C.; TRIGIANO, R. Variability of three isolates of Botrytis cinerea affects the inhibitory effectsof calcium on this fungus. Phytopathology, Saint Paul, v.90, n.7, p.769-774, 2000.

CROUS, P.W.; VERKLEY, G.J.M.; GROENEWALD, J.Z.; SAMSON, R.A. Fungal biodiversity. CBS Laboratory Manual Series. Utrecht: Westerdijk Fungal Biodiversity Institute, 2009. 269 p.DASHWOOD, E.; FOX, R. Infection of flowers and fruits of raspberry by Botrytis cinerea. Plant Pathology, Oxford, v.37, p. 423-430, 1998.

ELAD, Y.; WILLIAMSON, B.; TUNDZYNSKI, P.; DELEN, N. Botrytis spp. and Diseases they cause in Agricultural systems- An Introduction. In: ELAD, Y.; WILLIAMSON, B.; TUDZYNSKI, P.; DELEN N. (ed.). Botrytis: biology, pathology and control. Dordrecht: Springer, 2007. cap1, p.1-8.

ELLIS, M. B. Dematiaceous hyphomycetes. London: CABI Publishing, 1971. 608 p.

ESTERIO, M. Caracterización genotípica y fenotípica de la forma esclerocial de Botrytis cinérea Pers. en cv. Thompson seedless (Vitis vinifera L.) en dos localidades del valle central de Chile. 2005. Tesis (Maestria en Agr. Pec. Mención Producción Frutícola) Facultad de Ciencias Agronómicas, Universidad de Chile, Chile, 2005.

ESTERIO, M.;AUGER, J.; RAMOS, C.;ARANEDA, M.; MUÑOZ, G.; ROSALES; M. Molecular characterization of the genetic structure of Botrytis cinerea populations from table grapes (Vitis vinifera L.). In: REUNIÓN DE BIOLOGÍA VEGETAL, 2., 2007, Samtiago de Chile. Resumen [...]. Santiago de Chile: Pontificia Universidad Católica de Chile, 2007. p. 29-31. 
ESTERIO, M.; AUGER, J. Implicancias de la variabilidad genética en el control de Botrytis cinerea en vides en Chile: Resistencia a fungicidas. Aconex, Santiago, v.92, p.17-24, 2006.

ESTERIO, M.; RAMOS, C.; WALKER, A. S.; FILLINGER, S.; LEROUX, P.; AUGER, J. Phenotypic and genetic characterization of Chilean isolates of Botrytis cinerea with different levels of sensitivity to fenhexamid. Phytopathologia Mediterranea, Bologna, v.50, p. 414-420, 2011.

FEKETE, É.; FEKETE, E.; IRINYI, L., KARAFFA, L.; ÁRNYASI, M.; ASADOLLAHI, M.; SÁNDOR, E. Genetic diversity of a Botrytis cinerea cryptic species complex in Hungary. Microbiological Research, Jena, v.167, n.5, p.283-291, 2012.

FERRADA, E.E.; LATORRE, B.A.; ZOFFOLI, J.P.; CASTILLO, A. Identification and Characterization of Botrytis Blossom Blight of Japanese Plums Caused by Botrytis cinerea and $B$. prunorum $s p$. nov . in Chile. Phytopatholoy, Saint Paul, v.106, n.2, p.155-165, 2016.

FILLINGER, S.; LEROUX, P.; AUCLAIR, C.; BARREAU, C.; AL HAJJ, C.; DEBIEU, D. Genetic analysis of fenhexamidresistant field isolates of phytopathogenic fungus Botrytis cinerea. Antimicrobial Agents Chemotheraphy, Madison, v.52, n,11, p.39333940, 2008.

FORERO DE LA-ROTTA, M. C. Enfermedades de la mora de Castilla. Santa Fé de Bogotá: Instituto Colombiano Agropecuario, 2001. 135p.

FOURNIER, E.; GIRAUD, T. Sympatric genetic differentiation of a generalist pathogenic fungus, Botrytis cinerea, on two different host plants, grapevine and bramble. Journal of Evolutionary Biology, Basel, v.21, p.122-132, 2008. (1)

FOURNIER, E.; GIRAUD, T.; ALBERTINI, C.; BRYGOO, Y. Partition of the Botrytis cinerea complex in France using multiple gene genealogies. Mycologia, New York, v.97, n.6, p.1251-126,. 2005.

FOURNIER, E.; GIRAUD, T.; LOISEAU,A.; VAUTRINS, D.; ESTOUP, A.; SOLIGNAC, M.; CORNUET, J.; BRYGOO, Y. Characterization of nine polymorphic microsatellite loci in the fungus Botrytis cinerea ( Ascomycota). Molecular Ecology Notes, Oxford, v.2, p. 253-255, 2002.
GEEP, V.; VERO, S.; CASSANELLO, M. E.; ROMERO, G.; SILVERA, E.; GONZALEZ, P.; REBELLATO, J.; FERREIRA, Y.; BETANCUR, O. Resistencia a fungicidas en Botrytis cinerea en el Uruguay Fungicide Resistance in Botrytis cinerea in Uruguay. Agrociencia, Montivideo, v.16, p.97-107, 2012.

GIRAUD, T.; FORTINI, D.; LEVIS, C.; LAMARQUE, C.; LEROUX, P.; LOBUGLIO, K.; BRYGOO, Y. Two sibling species of the Botrytis cinerea complex, transposa and vacuma, are found in sympatry on numerous host plants. Phytopathology, Saint Paul, v.89, p.967-973, 1999.

GIRAUD, T.; FORTINI, D.; LEVIS, C.; LEROUX, P.; BRYGOO, Y. RFLP markers show genetic recombination (Botrytis cinerea) and transposable elements reveal two sympatric species. Molecular Biology and Evolution, Oxford, v.14, p.1177-1185, 1997.

HAMMER, Ø.; HARPER, D.; RYAN, P. PAST: Paleontological statistics software package for education and data analysis, Palaeontología Electrónica, Valencia ,v.4, p.1-9, 2001. Disponível em: http://palaeo-electronica. org/2001_1/past/issue1 01.htm. Acesso em: 28 nov. 2018.

ISENEGGER, D.; ADES, P. K.; FORD, R.; TAYLOR, P. W. Status of the Botrytis cinerea species complex and microsatellite analysis of transposon types in South Asia and Australia. Fungal Diversity, Dordrecht, v.29, p.17-26, 2008.

JOHNSTON, P. R.; HOKSBERGEN, K.; PARK, D.; BEEVER, R. E. Genetic diversity of Botrytis in New Zealand vineyards and the significance of its seasonal and regional variation. Plant Pathology, Oxford, v.63, n. 4, p.888-898, 2013.

KARCHANI, S.; GAUTIER, A.; RAIES, A.; FOURNIER, E. Geography, plants, and growing systems shape the genetic structure of Tunisian Botrytis cinerea populations. Phytopatholoy, Saint Paul, v.98, n.12, p.1271-1279, 2008.

KHAZAELI, P.; ZAMANIZADEH, H.; MORID, B.; BAYAT, H. Morphological and molecular identification of Botrytis cinerea causal agent of gray mold in rose greenhouses in centeral regions of Iran. International Journal of Agricultural Science and Research, Landover, v.1, n.1, p.19-24, 2010. 
KUMARI, S.; TAYAL, P.; SHARMA, E.; KAPOOR, R. Analyses of genetic and pathogenic variability among Botrytis cinerea isolates. Microbiological Research, Jena, v.169, n.11, p. 862-872, 2014.

LEROUX, P. Chemical control of Botrytis cinerea and its resistance to chemical fungicides. In: ELAD, Y.; WILLIAMSON, B.; TUDZYNSKI, P.; DELEN N. (ed.). Botrytis: biology, pathology and control. Dordrecht: Springer, 2007. cap.12, p.195-222. .

LI, L.; GUO, P.; JIN, H.; LI, T. Different proteomics of Ca $2+$ on SA-induced resistance to Botrytis cinerea in Tomato. Horticultural Plant Journal, Amsterdam, v.2, n.3, p.154-162, 2016.

MA, Z.; MICHAILIDES, T.J. Genetic Structure of Botrytis cinerea Populations from Different Host Plants in California. Plant Disease, St Paul, v.89, n.10, p.10831089, 2005.

MARTÍNEZ, F.; BLANCARD, D.; LECOMTE, P.; LEVIS, C.; DUBOS, B.; FERMAUD, M. Phenotypic differences between vacuma and transposa subpopulations of Botrytis cinerea. European Journal of Plant Pathology, Dordrecht, v.109, n.5, p.479-488, 2003.

MARTINEZ, F.; DUBOS, B.; FERMAUD, M. The role of saprotrophy and virulence in the population dynamics of Botrytis cinerea in vineyards. Phytopathology, Saint Paul, v.95, p.692-700, 2005.

MENDES, G.; GONÇALVES, V.N.; SOUZA, E.M.; KOHLHOFF, M.; ROSA, C.A.; ZANI, C.L.; COTA, B.B.; ROSA, L.; JOHANN, S. Antifungal activity of extracts from Atacama Desert fungi against Paracoccidioides brasiliensis and identification of Aspergillus felis as a promising source of natural bioactive compounds. Memórias do Instituto Oswaldo Cruz, Rio de Janeiro, v.111, p. 209-217. 2016.

MIRZAEI, S.; GOLTAPEH, E. M.; SHAMS, M.; SAFAIE, N. Identification of Botrytis spp. on Plants Grown in Iran. Journal of Phytopathology, Berlin, v.156, n.1, p.21-28, 2008.

MOLINA, G.S.; LA-ROTTA, M.C.; DE TORRES, E. Incidencia de infecciones quiescentes de Botrytis cinerea en flores y frutos de mora de castilla (Rubus glaucus Benth.). Agronomía Colombiana, Bogotá, v.22, n. 2, p.101-109, 2004.
NUÑEZ, T.; LEYVA, S.G.; RODRIGUEZ, J.E.; MARISCAL, L.A. Etiología y control de la necrosis de flores y pudrición de frutos de pepino en Morelos. Revista Chapingo. Serie Horticultura, Chapingo, v.19, n.2, p. $255,2013$.

PANDE, S.; GALLOWAY, J.; GAUR, P.M.; SIDDIQUE, K.H.M.; TRIPATHI, H.S.; TAYLOR, P.; MACLEOD, M.W.J.; BASANDRAI, A.K.; BAKR, A.; JOSHI, S.; KRISHNA KISHORE, G.; ISENEGGER, D.A.; NARAYANA RAO, J.; SHARMA, M. Botrytis grey mould of chickpea: A review of biology, epidemiology, and disease management. Australian Journal of Agricultural Research, Melbourne, v.57, n.11, p.1137-1150, 2006.

PANDE, S.; SHARMA, M.; KISHORE, GK.; SHIVRAM, L.; MANGALA, N. Characterization of Botrytis cinerea isolates from chickpea: DNA polymorphisms, cultural, morphological and virulence characteristics. African Journal of Biotechnology, Nairobi, v.9, n.46, p. 79617967, 2010.

PEAKALL, R.; SMOUSE, P.E. GENALEX 6: Genetic analysis in Excel. Population genetic software for teaching and research. Molecular Ecology Notes, Oxford, v.6, n.1, p. 288-295, 2006.

RAJAGURU, B.; SHAW, M. Genetic differentiation between hosts and locations in populations of latent Botrytis cinerea in Southern England. Plant Pathology, Oxford, v.59, n.6, p.1081-109, 2010.

RASIUKEVIČIŪT É, N.; RUGIENIUS, R.; SIKŠNIANIENE, J. B. Genetic diversity of Botrytis cinerea from strawberry in Lithuania. ZemdirbysteAgriculture, Akamedija, v.105, n.3, p.265-270, 2018.

REBORDINOS, L.; VALLEJO, I.; SANTOS, M.; COLLADO, I.; CARBÚ, M.; CANTORAL, J. Análisis genético y relación con patogenicidad en Botrytis cinerea. Revista Iberoamericana de Micologia, Barcelona, v.17, p. 37-42, 2000.

ROSEWICH, U. L.; KISTLER, H. C. Role of horizontal gene transfer in the evolution of fungi. Annual Review of Phytopathology, Palo Alto, v.38, p. 325-363, 2000.

SAMUEL, S.; VELOUKAS, T.; PAPAVASILEIOU, A.; KARAOGLANIDIS, G.S. Differences in frequency of transposable elements presence in Botrytis cinerea populations from several hosts in Greece. Plant Diseases, Saint Paul, v.96, n.9, p.1286-1290, 2012. 
SANHUEZA, G. Determinación de resistencia de diez aislamientos de Botrytis cinerea Pers. ex Fr.,obtenidos de frutos de arándano (Vaccinium corymbosum $\mathrm{L}$.), a cinco fungicidas. 2012. Tesis ( Ingeniero Agronomo) - Facultad de Ciencias Agrarias Escuela de Agronomía, Universidad Austral de Chile, Valdivia, 2012.

SUTY, A.; PONTZEN, R.; STENZEL, K. Fenhexamid - sensitivity of Botrytis cinerea: determination of baseline sensitivity and assessment of the resistance risk. Pflanzenschutz-Nachrichten Bayer, Leuverkusen, v.52, n.2, p.149-161, 1999.

TAMAYO, P.; PELÁEZ, A. Caracterización de daños y pérdidas causadas por enfermedades del fruto de la mora de castilla (Rubus glaucus Benth.) en Antioquia. In: SEMINARIO FRUTALES DE CLIMA FRÍO MOderAdo, 3., 2000, Manizales. Memorias [...] Manizales: Corpoica, 2000. p. 174-179.

TANOVIĆ, B.; DELIBAŠIĆG.; MILIVOJEVIĆ, J.; NIKOLIĆ, M. Characterization of Botrytis cinerea isolates from small fruits and grapevine in Serbia. Archives of Biological Sciences, Serbia,v.61, n.3, p. 419-429, 2009.

TROSKIE, A. M.; VLOK, N. M.; RAUTENBACH, M. A novel 96-well gel-based assay for determining antifungal activity against filamentous fungi. Journal of Microbiological Methods, Amsterdam,v. 91, n.3, p. 551-558, 2012.
VERCESI, A.; TOFFOLATTI, S. L.; VENTURINI, G.; CAMPIA, P.; SCAGNELLI, S. Characterization of Botrytis cinerea populations associated with treated and untreated cv. Moscato vineyards. Phytopathologia Mediterranea, Bologna, v.5, n.1, p.108-123, 2014.

WALKER, A.S. Diversity within and between species of botrytis. In: Fillinger, S.; Elad, Y. (ed.). Botrytis: the fungus, the pathogen and its management in agricultural systems. New York: Springer International Publishing, 2016.cap. 6, p.91- 125.

XIE, X.; ZHANG, Z.; CHAI, A.; SHI, X.; LI, B. Grey mould on leaf mustard caused by Botrytis cinerea, a new disease in China. Australasian Plant Disease Notes, Collingwood, v.11, n.23, p.1-4, 2016.

ZHOU, Y.J.; ZHANG, J.; WANG, X.D.; YANG, L.; JIANG, D.H.; LI, G.Q.; HSIANG, T.; ZHUANG, W.Y. Morphological and phylogenetic identification of Botrytis sinoviticola, a novel cryptic species causing gray mold disease of table grapes (Vitis vinifera) in China. Mycologia, Lawrence, v.106, n. 1, p.43-56, 2014. 